\title{
Organisational forms of science communication: the UK and Spanish European higher education systems as paradigms
}

\author{
Gabriela Ojeda-Romano ${ }^{1}$ - Viviana Fernández-Marcial ${ }^{2} \cdot$ Clare Wilkinson $^{3}$. \\ A. Erik Stengler ${ }^{4}$
}

Accepted: 1 December 2021 / Published online: 21 December 2021

(C) The Author(s) 2021

\begin{abstract}
As key elements in research and development systems, higher education institutions have been taking a leading role when it comes to communicating science and technology, but their performance has been inconsistent so far. In this critical and comparative study of the UK public engagement model and the Spanish scientific culture model, eighteen practitioners from higher education institutions across both regions were interviewed. A mixed qualitative data analysis has been performed identifying similarities and differences that unravelled the science communication management model in the two different higher education systems. This article provides evidence on how the institutionalisation of science communication is strongly influenced by key driving forces in the higher education context as well as the policies of administrations and other agents.
\end{abstract}

Keywords Public engagement - Science communication - Organisational communication · Institutionalisation $\cdot$ Engaged University

\section{Introduction}

In recent decades, science communication has gone from being a rara avis to becoming a necessary element in a world that is dependent on scientific and technological progress. In contrast to the thousands of years that have passed since the emergence of social communication of science, there are a meagre six decades in which concern for these practices has

Gabriela Ojeda-Romano

gojeda@iim.csic.es

1 Engagement With Society Unit, Institute of Marine Research (IIM-CSIC), Spanish National Research Council, Eduardo Cabello 6, 36208 Vigo, Galicia, Spain

2 Department of Humanities, Faculty of Humanities and Information Science, University of A Coruña, Ferrol, Spain

3 Science Communication Unit, Faculty of Health and Applied Sciences, University of the West of England, Bristol, England

4 The Cooperstown Graduate Program, SUNY Oneonta, Oneonta, NY, USA 
entered the agenda of governments. Governments and institutions started to recognise the need for counting on scientifically cultured or educated societies for the advancement of nations, putting in place measures-more or less successfully-to accomplish it. Many of those actions have been aimed at the main agents of research and development systems to stimulate, support and consolidate their commitment to science communication. This has allowed the amateur practice of science communication, based on the voluntarism of a few, to be replaced — or at least reinforced — by a reality where professionalisation has begun to be the norm (Ferrando González \& Tigeras Sánchez, 2015).

In research organisations, including both research centres and higher education institutions (HEIs), science communication is increasingly present, sometimes with blurred boundaries with other related areas such as marketing or public relations. Aware of this overlap in many scientific institutions, Weingart and Joubert (2019) advocate for restoring the distinction between two types of science communication: communication that educates, informs and engages the public through dialogue and communication that promotes and persuades with the aim of legitimise political institutions. It is undeniable that the 'professionalisation' of science communication in research institutions may take different forms, yet there is a general lack of knowledge regarding the 'organisational turn' in science communication (Schäfer \& Fähnrich, 2020). In recent years, several authors made evident this shortage, pointing out the scarcity of studies analysing how organisational contexts influence science communication (Elken et al., 2018; Entradas \& Bauer, 2017; Entradas et al., 2020; Rodder, 2020; Schäfer \& Fähnrich, 2020; Schwetje et al., 2020). A few studies have been recently conducted to address this gap, including: some studies that measured the level of the institutionalisation of science communication in research organisations (Vargiu, 2014); others that explored the perceptions of researchers and communication professionals on their science communication practices (Koivumäki \& Wilkinson, 2020); some projects which measured research centres' performance on public engagement (PE) at a national level (Entradas \& Bauer, 2017; Featherstone et al., 2009) or across countries (Entradas et al., 2020; Neresini \& Bucchi, 2011); whilst others analysed the communicators and communication units in HEIs (Schwetje et al., 2020).

These studies do not offer sufficient evidence to make general assumptions about the climate for science communication in specific countries, making the need for further research in this area all the more pressing. Schäfer and Fähnrich (2020) called for research on the already mentioned 'organisational turn' in science communication, asking for more scholarly emphasis on science communication from the fields of strategic communication and communication management and vice versa. Besley (2020) has stressed the urgency for understanding at a practical level, calling for 'a more strategic, organisation-focused approach to science communication' (p.155), with less dependency on individual communicators in favour of strengthening the role of organisation-based teams. Following these calls for action, the present study is intended to advance knowledge and help in understanding aspects of the organisation of science communication in institutional settings.

We explore how the institutionalisation of science communication is translated into practice in the higher education (HE) systems of the United Kingdom (UK) and Spain. Selecting these countries allows an in-depth comparison as they represent examples of two very different science communication practices, performances and cultures. On the one hand, the UK has a long tradition in fostering science-society interfaces, having been the driving force behind milestones such as the public understanding of science paradigm with the publication of the 'Bodmer Report' in 1985 by the Royal Society (Bodmer, 1985) as well as the shift to public engagement with the report on Science and Technology by the House of Lords (House of Lords, 2000). To this day, the UK continues to strengthen the 
university context for communication and engagement with several public and private initiatives as well. On the other hand, Spain presents itself as a country with a shorter history and a late start, but that has undergone a major transformation in recent years and seems to harbour a growing commitment to science communication.

This article focuses on one of the most recent science communication organisational forms that has emerged, that of 'specialised science communication and engagement units'. They were born out of the institutionalisation process that has taken place in research organisations around the world, and depending on the country and the type of institution, these units tend to adopt different forms but similar commitments. Despite their relevance, they are almost unexplored, Watermeyer and Lewis' work (2018) being one of the few studies that shed some light on this issue and which has considered the state of the art of PE from the perspective of dedicated professional service (support and administrative) staff working within UK universities. Spain does not have exhaustive reviews of the science communication units in institutional settings either, with only a few studies offering fragmented results (FECYT, 2015; Ojeda-Romano \& Fernández-Marcial, 2018; Parejo Cuéllar et al., 2017; Roca Marín, 2017).

Unlike other studies, the originality of this project is that it adopts a cross-national approach in which different science communication cultures are taken into account, focussing on specialised organisational forms of science communication. We analyse the science communication and engagement units by presenting the results of an exploratory and descriptive study, which encompasses (1) an extensive literature review and (2) a qualitative analysis of homologous departments in both UK-based and Spanish HEIs through semi-structured interviews of experts. With this research, we aim to shed light into the institutionalisation process of science communication in UK-based and Spanish HEIs, by understanding how science communication is managed and articulated within these two HE systems.

\section{HEls' transition to 'modern' organisations}

Why HEIs? The relevance of these institutions is given by their dual teaching-research role, which makes them essential actors in any developed country. HEIs are major pillars in the production of scientific knowledge, being responsible for a great percentage of the research carried out in the world, so their contribution to economic and social development is undeniable.

HEIs have undergone major changes in the last decades, challenged by demands asking them to be greater contributors to the global knowledge economy and to cultivate stronger relationships with the public (Watermeyer, 2016; Watermeyer \& Hedgecoe, 2016), which also triggered the emergence of university performance's measurements such as benchmarks, rankings and branding (Elken et al., 2018). This changing climate led HEIs to work towards consolidating their reputations, competing for attracting students and exploiting knowledge in an 'entrepreneurially' way. As a result, managerial aspects of HEIs have been affected, including a higher professionalisation and specialisation of management tasks and staff (Drori, 2013). For instance, communication services became 'more comprehensive and larger [...] at central level' (Elken et al., 2018, p. 1118), placing emphasis on public relations, corporate communication or marketing, to deal with the raise in competition among institutions. Science communication and PE initiatives have been reported to be valuable branding and communication tools, impacting positively in researchers' and HEIs' external image and helping in achieving public support (Blanton, 2007). In fact, Lo Presti 
and Marino (2019) consider PE 'as a communication level of university's positioning from a social perspective' (p. 91).

Likewise, the academic practice within HEIs has experienced a deep transformation due to the shift in the public role of universities. Some countries, such as New Zealand, Australia or Hong Kong, have implemented performance-based research funding systems, following the UK's trail and its Research Excellence Framework (Watermeyer, 2014; Chubb \& Watermeyer, 2016). In these systems, reporting the economic and societal impact of research is essential for academics to be funded and positively evaluated. Thus, the 'impact-agenda' changed the rules of the game, and academics found themselves trapped in a new dynamic where intellectual excellence is not enough to succeed (Chubb \& Watermeyer, 2016; Watermeyer, 2016; Watermeyer \& Tomlinson, 2021). In this context, PE has been recognised as relevant to capture and measure part of that societal impact (Reed et al., 2018). However, performing PE in a performance-based research funding system context has encountered discrepancies 'between the valuation of public engagement as a form of impact against engagement as a road to impact' (Watermeyer, 2012, p. 118) and barriers such as incompatibility with academic time compartmentalisation, intensive labour and conflict with organisational structures (Watermeyer, 2014, 2016). Notwithstanding, academics have increased their efforts when interacting with external communities (Chubb \& Watermeyer, 2016) in order to fulfil research funders' and regulators' pressures, giving PE greater credence and tacit momentum (Watermeyer, 2012).

\section{Institutionalisation of science communication: evolution and embedding in HEls}

Currently, science communication in university institutional settings "covers a wide spectrum from fully instrumentalised science communication serving narrow promotional purposes to embedding public dimensions of research into academic structures' (Trench, 2017, p. 1). The main modes that stand out are communication of research findings, consultancy and support to projects involving society at some point, training researchers and technical staff in science communication and science communication activities. ${ }^{1}$

The relevance ascribed to science communication as well as the progressive embedding of its different modes within the HEIs' environment seems to be related to a change in the conception of the 'Third Mission' of HEIs. Aware that in recent times HEIs were prioritising those actions that had economic value over those implying another type of relationship with society, several authors emphasised the need to cover other ways in which institutions may interact with the public (Molas-Gallart et al., 2002; Vargiu, 2014). Those ways include disseminating research results; inspiring Science, Technology, Engineering and Mathematics (STEM) careers; enabling citizens to participate in research; and working towards more socially responsible research, among others. This conception of the Third Mission is based on the Engaged Campus' philosophy (Beere et al., 2011; Fitzgerald et al., 2012; Furco, 2010; Pinheiro et al., 2015), which postulates engagement must be integrated into all

\footnotetext{
1 Science communication activities are initiatives aimed either at the general public or at specific audiences that can range from the most traditional ones that seek to inform, inspire and/or educate the public (science festivals, workshops in schools, talks, etc.), going through to those which want to involve society in research with citizens as an active part of the scientific knowledge production (RRI, citizen science, etc.), to activities that encourage a shared decision-making process, taking into account recommendations of stakeholders (Ravn et al., 2014; Rowe \& Frewer, 2005; Reed et al., 2018).
} 
university missions to achieve meaningful research and effective teaching, as stated in the National Coordinating Centre for Public Engagement's website, as of December 20, 2018.

Despite what has been the catalyst for the inclusion of some of the modes of science communication as institutional remits, this process has been inconsistent (Watermeyer \& Lewis, 2018). There has not been a uniform type of structure that spearheaded these practices, resulting in the involvement and creation of a great variety of departments. In many cases, existing teams or departments such as communication offices or knowledge transfer services adapted some of their roles to cover this need. In other cases, new structures were created to assume these science communication modes, the so-called science communication and engagement units. In this study, we define these units as the basic structures through which science communication is being articulated in the HE systems. Their main characteristics include (1) at a functional level, being the facilitating nucleus for connecting research with non-expert audiences through the already mentioned science communication modes; (2) at a formal level, they can have varied structures in the organisational model of the each institution, but they usually operate as general services for the entire HEI or for specific faculties or research hubs; and (3) at a compositional level, units can encompass professionals and technicians with a degree of specialisation in science communication. Accordingly, the types of science communication and engagement units falling into this description and that have emerged in different countries and institutions could be considered homologous departments.

Although each institution has had a different development, the institutionalisation of science communication in HEIs seems to follow certain trends depending on the country. Spain and the UK are not the exception, and in order to delve into the paths they have followed, a terminology aspect has to be considered first. We will refer to 'scientific culture' (SC) and 'public engagement' (PE), respectively, for the Spanish and the UK-based HE systems, as synonyms for 'science communication'. Having accepted the impossibility of establishing absolute equivalences without a proper analysis-which is beyond the scope of this paper-we will use both terms, as they are predominant in each country and accurately reflect the local context when it comes to the practical side of science communication.

\section{Public engagement (PE) management model for the UK HE system}

Under the philosophy of the Engaged Campus (Beere et al., 2011; Fitzgerald et al., 2012; Furco, 2010), the institutionalisation of PE with research has taken root in the UK over the last decade. Since 2008 and thanks, in part, to the influence of the 'Survey of Factors Affecting Science Communication by Scientists' published by the Royal Society (Royal Society, 2006), a series of interventions and initiatives were established to simultaneously promote a culture that supports, rewards and recognises PE (Duncan \& Manners, 2012; Owen et al., 2016; Watermeyer, 2015). These actions were carried out by organisations including the UK Research and Innovation (an umbrella organisation for UK research councils), the Wellcome Trust and the Higher Education Funding Councils.

The two most relevant initiatives that contributed to shape PE in the UK HE system were the Catalysts Initiative (Townsley, 2016) and the 'Beacons for Public Engagement' call (Webster et al., 2010). The first initiative aimed to integrate PE into policies, procedures and practices of HEIs. Grants were awarded to eight institutions, some of which established what are now called public engagement units (PE units), while others involved academic or professional services staff as coordinators. The second call supported the creation of six beacons made up of HEIs and the National Coordinating Centre for Public 
Engagement, which was created to support, recognise, reward and develop capacities for $\mathrm{PE}$ in the UK. However, the National Coordinating Centre for Public Engagement's work has gone beyond the duration of the Beacons funding (Duncan \& Manners, 2012) and has become a fundamental driver of the institutionalisation of PE in the UK HE system.

The evolution of PE in HEIs in the UK has also been influenced by the growing concern about the economic and societal impact of research (Hughes \& Kitson, 2012; Owen et al., 2016; Watermeyer \& Lewis, 2018; Wilkinson, 2017) and its measurement within the Research Excellence Framework, responsible to some extent for the rising interest in PE and its institutional configuration in recent years (Wilkinson, 2017). In this context, the first formally dedicated PE departments and units emerged in UK-based HEIs. These PE units were added to other structures that were already dedicated to related areas such as Outreach, ${ }^{2}$ Widening Participation or Press offices. The establishment of these units entailed not only an organisational change within the institutions, which suddenly created departments or services allocating personnel and resources, but also a shift in the way of dealing with this phenomenon of communication and engagement at a strategic level, with science communication and PE becoming necessary tools to achieve institutional goals.

\section{Scientific culture (SC) management model for the Spanish HE system}

On the Spanish scene, the support promoted by the government in recent decadesalthough limited-was a significant step forward. The first mentions of SC in the Research and Development Spanish regulation date back to the year 2000 with the National Research and Development Programme (2000-2003), but it was not until years later that a national funding stream for SC activities was created within the Programme for Communication and Dissemination of Science and Technology of the National Research and Development Programme for 2008-2011 (CICYT, 2007).

This call for funding, launched in 2007 and managed by the Spanish Foundation for Science and Technology (FECYT), continues to be offered today. It targets the agents of the Spanish research and development system and sets the grounds for the current Spanish scientific culture system at institutional level. Some of the most impactful initiatives have included the development of a Scientific Information and News Service, a Local Network of Scientific Culture Agents and a Science and Technology Museum Network. In addition, it contributed to the establishment of specialised departments in science communication, providing funds both for the existing units, ensuring their consolidation, and for brand new ones, the so-called Units of Scientific Culture and Innovation-SC Units or UCC $+\mathrm{i}$ (for its Spanish name).

Thus, the SC units are the product of the institutionalisation of SC in Spain and the main components of this phenomenon at the national level. FECYT has played a key role in its development as not only it manages the call, but it also provides the units with a common formal framework, establishing the guidelines which would lead their future work. The 'White Paper report on the scientific culture and innovation units, SC Units' published by the FECYT in 2012 (FECYT, 2012) is a guide which includes detailed parameters defining

\footnotetext{
${ }^{2}$ Outreach corresponds to the programmes, services, activities and/or experiences for those outside the university community, with a unidirectional approach (one-way), so there is neither dialogue nor collaboration with the public (Beere et al., 2011). Some authors make a distinction indicating that outreach would be science communication activities aimed at primary and secondary school students and that, in general, would be focused on inspiring STEM careers as stated in the University of Bath's website as of January 15, 2018.
} 
these departments: a classification, their potential audience, the impact indicators to measure the units' performance as well as their action lines, including SC units that communicate research and development results, that carry out science communication activities, that provide consultancy and training to academic staff and that do research into social aspects of science and technology. There have been no other actions of the magnitude of the FECYT's call in the Spanish context, neither from the central administration nor from other collaborating entities. Only a few smaller programmes have been launched to emphasise the promotion of SC, most of them at the regional level and with limited impact.

At this point, we may state that advancing in the knowledge of the UK and the Spanish science communication models and their institutionalisation in HE-the main goal of this research-will allow the pinpointing of problems as well as sharing good practices, which may be crucial to strengthen them further and to contribute to a better management of science communication initiatives. This paper will respond to these challenges and, therefore, attain the main goal of this study by understanding how science communication is managed and articulated within these two HE systems. The key elements in order to do so are the specialised science communication and engagement units, which have two essential aspects: structural and functional characteristics as well as influencing factors. Hence, the research questions are as follows:

$R Q 1$. What are the differences and common features among the science communication units of both HE systems from a structural and a functional perspective?

$R Q 2$. What are the main drivers and key factors influencing science communication organisational forms adopted by HEIs in the Spanish and the UK contexts?

\section{Methodology}

This article is a critical analysis of the homologous structures that articulate the science communication models of the UK-based and Spanish HEIs. This exploratory and descriptive study, based on semi-structured interviews with experts, adopted a qualitative approach to characterise and evaluate these models. An interview schedule of 18 open-ended items was designed (Annex 1).

\section{Sample and data collection process}

Regarding the sample frame, or sample universe, it included all of the departments or units in charge of fostering science communication in UK-based and Spanish HEIs. Those who met the selection criteria described in Annex 2 were contacted to compile a representative sample. A total of 18 entities, 7 from the UK and 11 from Spain, participated in the research. The interviews specifically targeted the directors and coordinators of the units. Interviews at UK-based HEIs took place in situ, with a face-to-face interview, while the Spanish ones were conducted through written questions administered by e-mail. Contacts and meetings took place between November 1 and December 10, 2017.

\section{Analysis}

Due to the structure of this research and the nature of the data, a qualitative analysis with an inductive, semantic and realistic approach was performed with both data sets. After 


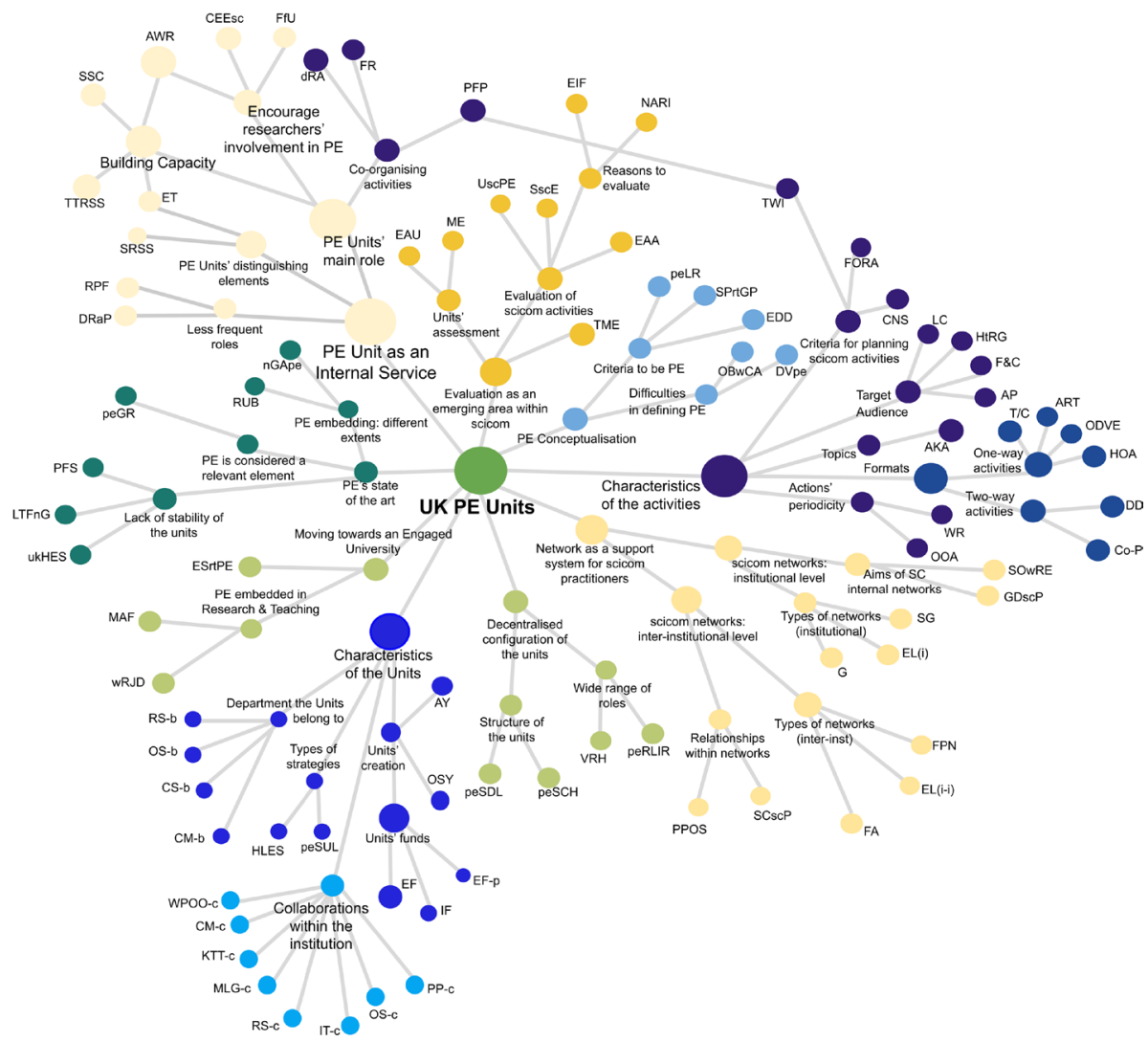

Fig. 1 Codes, categories and themes identified for UK PE units

transcription and assignment of an identification number (UK1to UK7 for the UK-based interviews and E1 to E11 for the Spanish ones) to preserve the confidentiality of the interviewees, the data were coded following the stages described by Braun and Clarke (2006) and supported by the qualitative software ATLAS.ti. A mixed analysis was carried out incorporating content analysis and thematic analysis. On the one hand, this approach allowed us to group into categories those codes according to frequency value (Vaismoradi \& Snelgrove, 2019), and on the other hand, it favoured the creation of themes that allowed for a more exhaustive, deep and abstract interpretation (Braun \& Clarke, 2006; Fereday \& Muir-Cochrane, 2006; Javadi $\&$ Zarea, 2016). The analysis included 759 quotes that were coded 816 times by 119 different codes, organised in 46 categories and subcategories, and 12 different themes as shown in Figs. 1 and 2. Themes are presented in Table 1. All codes, their definitions, example quotes, along with other metrics, are listed in Annex 3. 


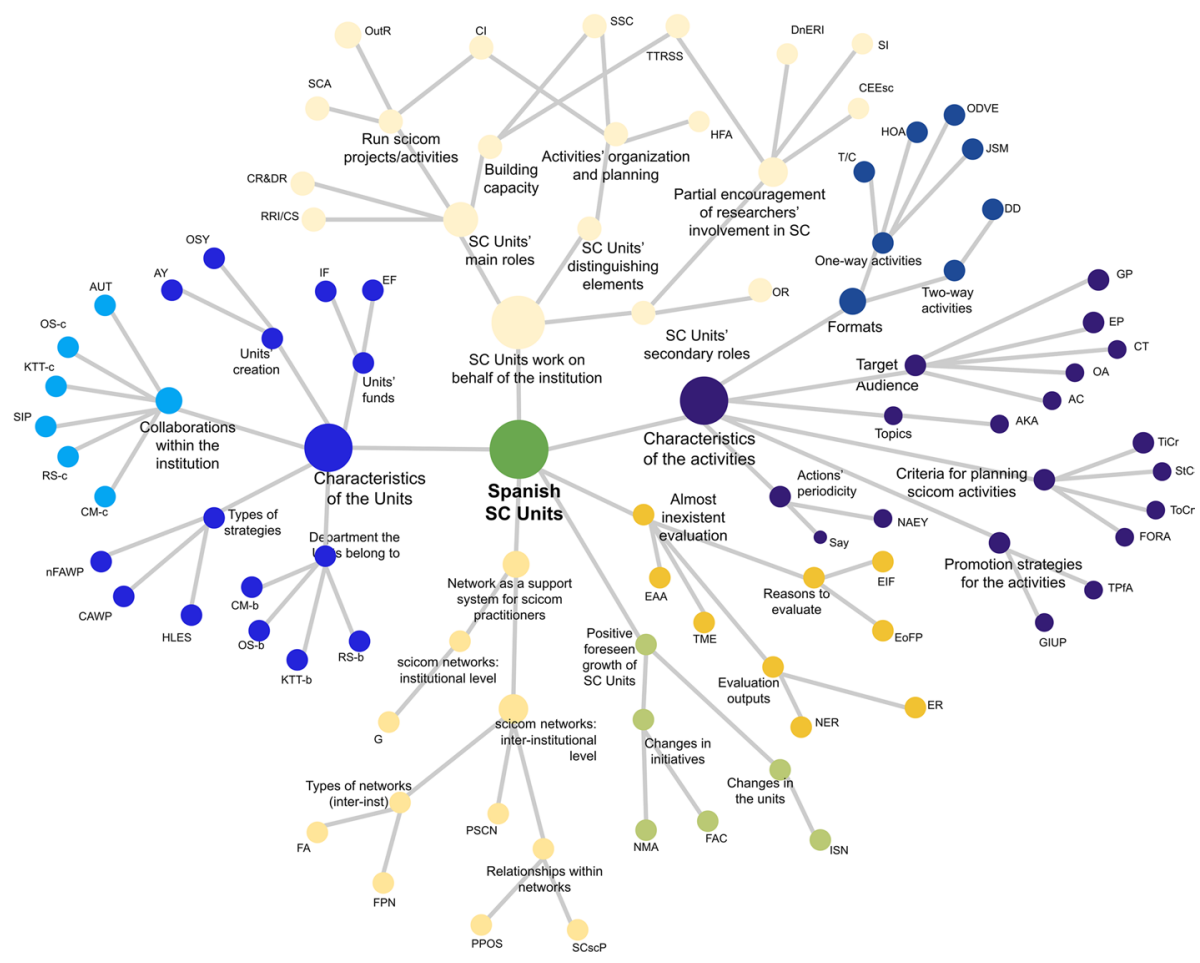

Fig. 2 Codes, categories and themes identified for Spanish SC units

\section{Results}

\section{Launch of the units and strategies}

Comments regarding the year the units were launched shed some light on the origin of the institutionalisation of science communication, since there was observed parallels between the different periods in which the units seem to have been established and the main science communication funding calls in both regions: the first period (years 2007/2008) corresponds to FECYT's first call in Spain and the Beacons for Public Engagement call in the UK and the second (years 2012 to 2014) to the Public Engagement with Research Catalysts project in the UK.

The SC Unit of our university appears for the first time in September 2008, due to FECYT funds. (E5) ${ }^{3}$

Although most of the SC units were established earlier than the PE units, this does not mean that the science communication model in Spanish HEIs came first: Outreach and Widening Participation programmes already existed in many UK HEIs, and the dates

\footnotetext{
${ }^{3}$ Original quote: 'En septiembre de 2008 aparece por primera vez la UCC de nuestra universidad gracias a una ayuda de FECYT.'.
} 


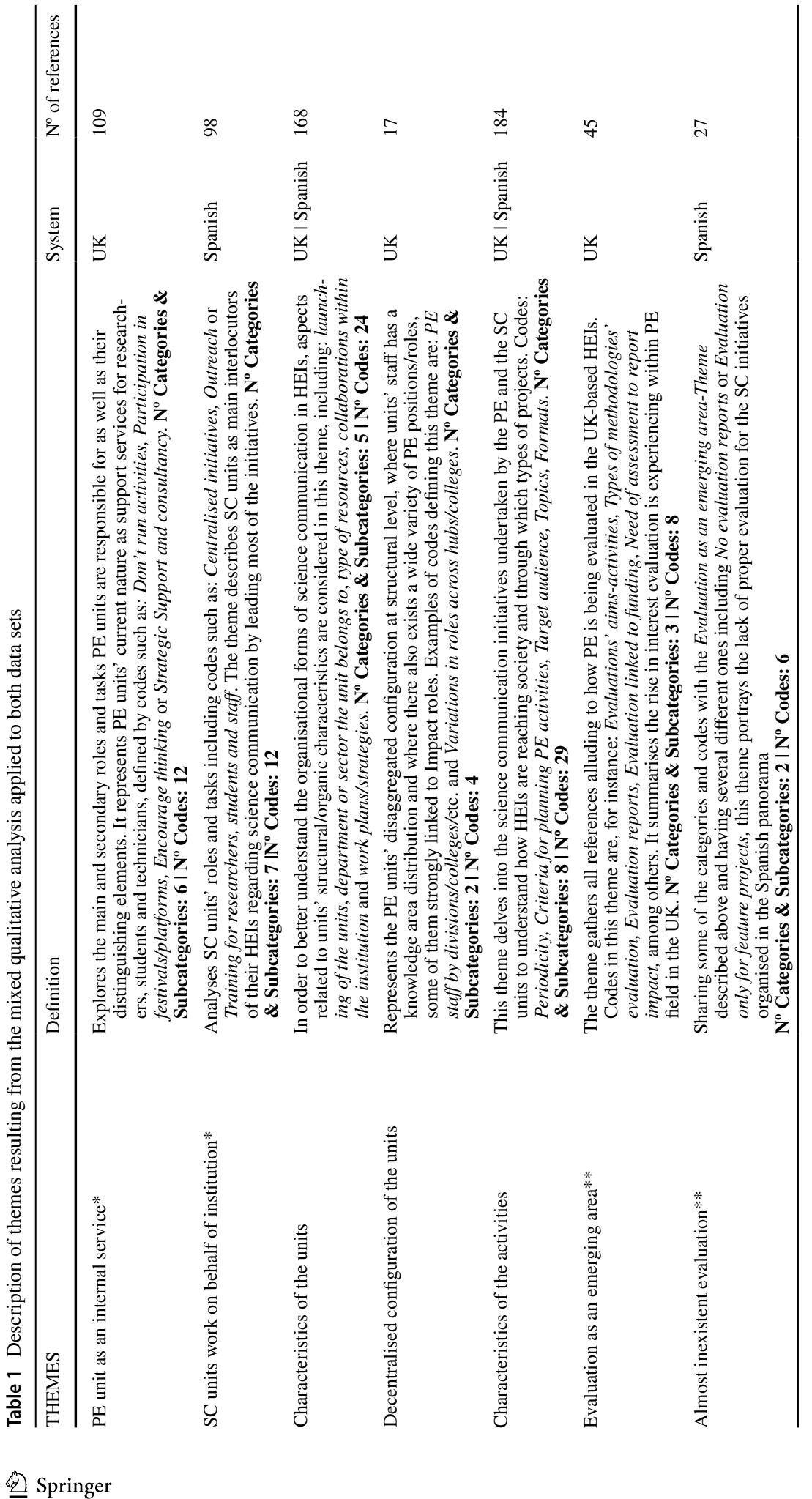




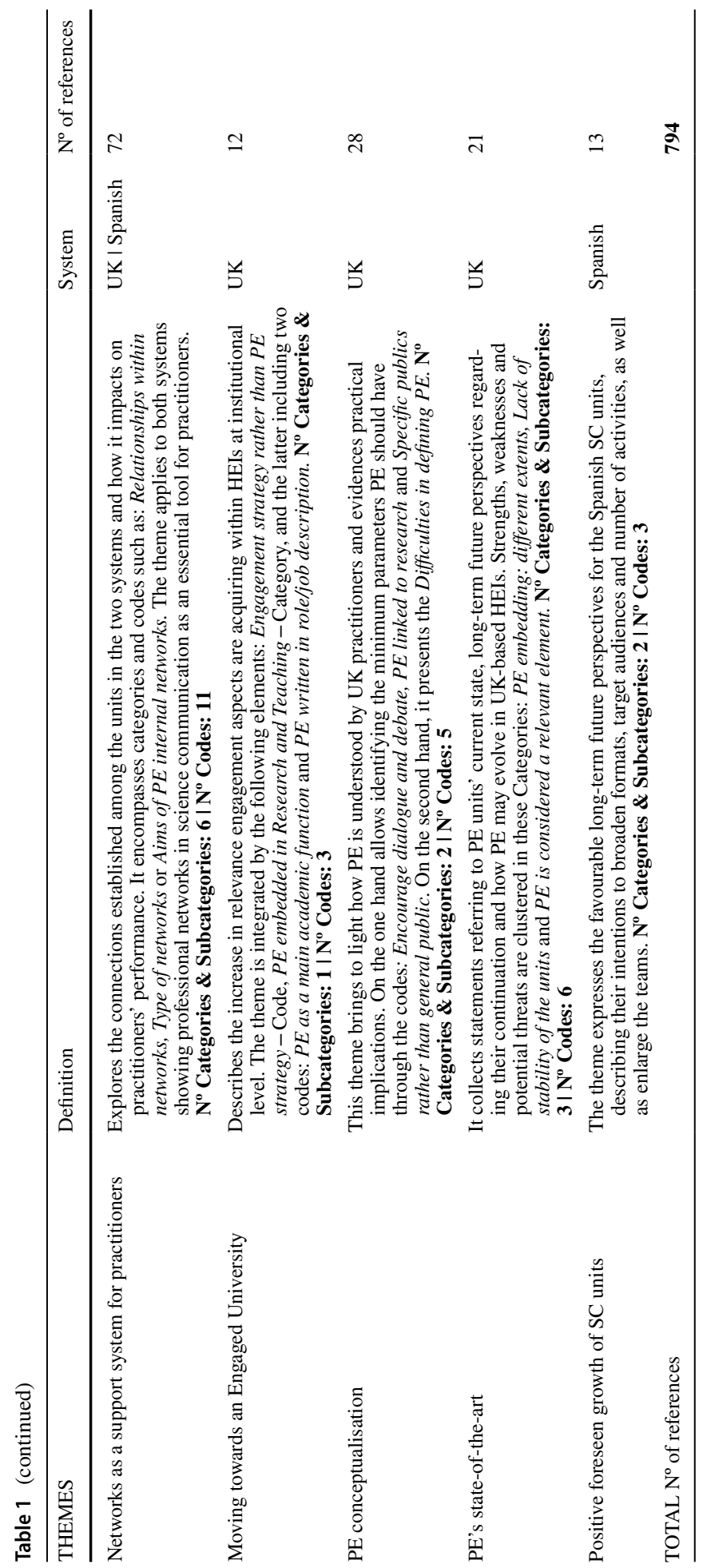

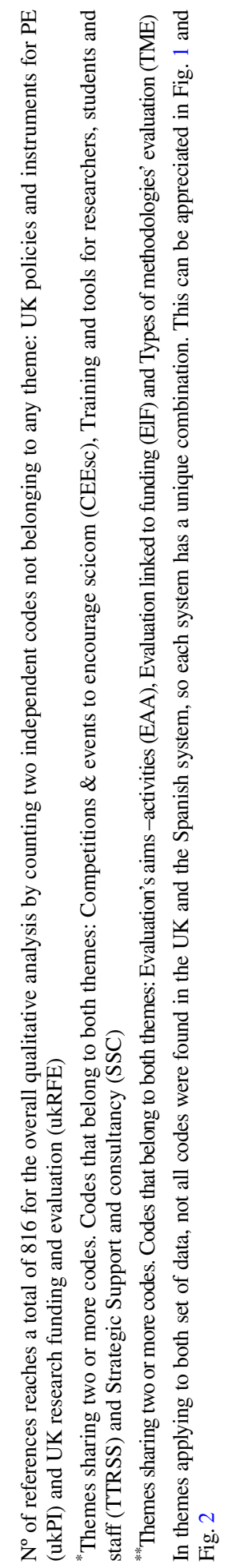


reported for these correspond to a milestone of specialisation towards the new model of PE in the UK rather than a start of operations.

All 18 units had or were developing a PE/SC strategy at the moment of the interviews, and three types were identified: (1) annual work plans (describing what actions and how they will be carried out during the academic year), (2) PE/SC strategies at department level (including goals, values and aims of the units) and (3) strategies at institutional level (including PE/SC elements in a university-wide strategy). While the annual work plans are the predominant type of strategy in the SC units, a departmental level strategy was mentioned by half of the PE units:

We have just this, within the last six months created a strategy for the unit, which is a different thing to a public engagement strategy for the university. [...] It's basically, all it is writing down what we do, and justify what we're doing. (UK4)

The third type, institutional strategy, was referenced only in a few UK PE units. The latter cases were grouped under the theme 'Moving towards an Engaged University' - Theme, which was found exclusively in the UK system, with two key aspects: those HEIs which include high-level strategies ('Engagement strategy rather than PE strategy'-Code) and those which represent incipient efforts to include PE in research and teaching ('PE embedded in Research and Teaching' - Category) following the Engaged University philosophy:

We have a new strategy coming out in January... [a] specific mission strategy. Rather than engagement, it's much broader. So it looks at elements corporate responsibility, sustainable development, equalities... It also looks at jobs, and partnerships and organizations as well as your traditional research impact and engagement, public engagement in schools and community engagement. So it's a much broader strategy.

(UK1)

\section{Funding}

In general terms, it was reported that the main funding sources were national programmes aimed at promoting SC and PE. It was also salient that there was a greater number of organisations offering funds in the UK than in Spain, where funding is almost exclusively limited to the FECYT's contributions.

The SC Unit co-funds their projects thanks to public funding calls such as FECYT's. $(\mathrm{E} 8)^{4}$

One difference is that the FECYT's calls take place yearly, providing the SC units with certain security, while the UK PE funding programmes, with few exceptions, are not usually periodic, and their objectives can vary, meaning that the same PE unit may not necessarily have been eligible for all of them. In both Spain and the UK, some units and departments also declared having access to funds from international calls, including the Marie Skłodowska-Curie actions.

Regarding their own funds, in the Spanish landscape, the representatives of the units reported having access to a core budget from their institution. In the UK, some of the units also declared receiving partial institutional funding; however, they indicated the need to

\footnotetext{
${ }^{4}$ Original quote: 'La UCC $+\mathrm{i}$ cofinancia sus proyectos mediante convocatorias públicas como las de la FECYT.'.
} 
have other ways to obtain income, such as internal calls, budget items from research projects for outreach and engagement elements or hiring PE staff indirectly through impactrelated jobs. In the thematic analysis, references to these funding means and their influence in the configuration of the current UK PE model are collected within the code 'UK policies and instruments for PE' - Code:

There are other large projects in the institution where the academics can get money to do PE. There is also external funding which we apply for in the UK that most of the funding bodies have PE elements and support those to develop and deliver PE if they have a grant for them or anything else. (UK7)

\section{Organisation of the units}

The results of the analysis indicated a different structure of the units in the two systems. In the UK context, a 'Decentralised configuration of the units' - Theme was appreciated. In most of the cases, PE units were not a single department but a network of small teams belonging to the different knowledge hubs, usually linked by a central coordinator but with a lack of a hierarchical component. There was also a wide variety of PE positions/ roles, whose names and duties also varied according to area and institution ('Wide range of roles' - Category).

[...] the central post coming in, who's let say this person, who is a senior facilitator in coordinating public engagement, she is sitting in research services. She sort of had the mandate to bring together a group. She brought together people from each academic division who had public engagement roles. [...] So for myself and my equivalent in the sciences, we are a full time person working on public engagement, but in the humanities and social sciences, they are not. (UK2)

This fragmented pattern was not replicated in the Spanish units since they had a single central nucleus. Any SC unit is only one department giving support to the entire institution with a fixed core staff group with different profiles (editors, scientific advisers, audio-visual technicians). However, on top of that main and central unit, most Spanish HEIs have other secondary structures at the level of faculties, research centres or groups. The differences with the UK are that Spanish sub-structures are usually temporary, independent from one another and from the main SC unit, lacking a central coordination and with no relevance in the organisation scheme of the HEI.

\section{Affiliation, collaboration and networks}

While research services stood out as the predominant area PE units are attached to, the affiliation of the SC units is more variable including other areas such as communication, technology transfer or outreach. These data evidence the emergence of science communication at the institutional level, at least in Spanish HEIs, as a change in the Third Mission's conception.

Regarding collaborations with different sectors or departments within the institution, almost half of the SC units' interviewees confirmed that they work independently, while the remainder tended to collaborate mainly with the Marketing and Communication Department and also with Technology/Knowledge Transfer offices and Technology Parks. 
I practically do them [science communication initiatives] autonomously, with an important collaboration of the communication office when developing press releases or to advise us on relevant research and researchers. (E5) ${ }^{5}$

For their part, interviewees from PE units acknowledged that they closely collaborate with many divisions and that they did not carry out their projects unilaterally in any case. In terms of how SC/PE practitioners are connected through professional networks, multiple intra- and inter-institutional alliances and groups were detected and documented as 'Support systems for SciCom practitioners' - Theme. All units reported to belong to at least one network and to be in regular contact with their counterparts. The results suggest that networks, characterised by fostering shared projects and a collaborative spirit, are an essential element for science communication professionals to develop their work, drawing expertise from the rest of the community.

\section{Units' roles}

The study has revealed that roles are not assumed in the same way or with the same emphasis in the different institutions; each of which has a specific combination of tasks and a unique way of approaching science communication. Even so, when comparing the two systems, a series of common trends were detected, and main roles were also identified.

Organisation of science communication activities, understood as the design and execution of science communication initiatives, was listed as the main role of SC units, including 'Training and tools for researchers, students and staff' - Code, informal and non-formal activities for youngsters and other science communication actions. In contrast, in the UK system coordinating activities appeared as an almost extinct task. PE units experienced a shift moving from holding science communication events to only providing support ('Former role'-Code), claiming that it is no longer necessary for the units themselves to create this type of opportunities because the UK's landscape has changed and these type of initiatives are very popular:

We don't need to be manufacturing these opportunities, because there're so many types of festivals that people could get involved in, opportunities of all kinds of public talks and events that they don't need us to create new opportunities for that sort of very standard engagement work. (UK5)

Another significant difference is that organising specific informal and non-formal educational programmes for children is not a PE units' role in the UK, as it is taken on by other departments such as Outreach and Widening Participation units. On the contrary, within the SC units, undertaking these programmes appears as a major task within their remit since a large part of the actions target students and young people, as addressed in the Discussion section below.

From the SC Unit, we make an special effort to undertake science communication activities for pre-university publics in order to inspire STEM careers. (E10) ${ }^{6}$

\footnotetext{
5 Original quote: 'Prácticamente las realizo de forma autónoma, con una colaboración importante del gabinete de comunicación a la hora de desarrollar notas de prensa o aconsejarnos en investigadores e investigaciones importantes.'.

${ }^{6}$ Original quote: 'Desde la UCC + i se realiza un especial esfuerzo por llevar acciones de divulgación de la ciencia a públicos preuniversitarios para fomentar las vocaciones científicas.'.
} 
As for 'Building Capacity' - Category or support and training of researchers, students and other university staff in science communication, half of the interviewees' SC units had a well-developed range of communication and SC courses available ('Training and tools for researchers, students and staff' - Code). However, 'Strategic Support and consultancy'-Code appears as a less common element, and not all SC units consider it. In the UK system, 'Building Capacity' - Category was more relevant, and training and support were equally important:

The second element is around the capacity of development, so it's working with academics and professional services staff across the university in order to be able to improve the quality of engagement that our staff and students are able to do part of that role. (UK1)

'Encourage Thinking' - Code was another element detected in the UK system that was absent in the Spanish one. It represents the effort made by PE units to bring about a culture change regarding the role played by $\mathrm{PE}$ in research. It constitutes an attempt to instil what public communication implies and what it consists of, making those who are involved think about deliberative and collaborative formats and consider specific types of public. This parameter was not only part of the 'Building Capacity' - Category role but was related to other categories and topics, having great influence and being a salient element of the UK science communication system.

'Encouraging researchers' involvement'-Category was identified as a compilation of initiatives to motivate the academic community to do science communication. It was closely related to 'Encourage Thinking' - Code, since it could be considered the materialisation of part of that concept: means and tools to foster PE/SC and instigate that culture change. In the UK system, this role was a strong branch with multiple elements such as funding calls to organise events or awards that recognise science communication work. None of the interviewees from participating SC units mentioned it when they were asked about their tasks. However, in response to the question 'Does the unit have any plans to encourage different departments to get involved in science communication?', seven out of 11 gave a positive answer and pointed out some initiatives such as face-to-face meetings with departments, institutes and research groups.

Finally, it was verified that the communication of research and development results is a role assumed by a large number of the SC units, despite this being traditionally carried out by the institutional press offices. In UK-based HEIs, it is the task of research communication or press offices, depending on whether there are both or only one, but in no case was it reported as the PE units' responsibility.

In summary, two different trends were identified. On the one hand, 'SC Unit work on behalf of the institution' - Theme that describes the SC units as external services, whereas 'PE Unit as an Internal Service' - Theme indicates that PE units work with and for researchers, students and other university staff.

\section{Activities and events}

From the data, we conclude that, both in the Spanish and the UK units, science communication initiatives cover all knowledge areas in the institution, including social sciences and the humanities. Both systems seek to incorporate new actions each academic year, but there is also a certain level of recurrence. SC units repeat successful activities several 
times, while an important component of 'institutional tradition' drives UK-based HEIs to participate in recurring science festivals in particular.

But there are a lot of initiatives that continue. Cheltenham Science Festival is every year. Someone from the university goes every year. There's always been these things that continue to happen. (UK5)

The one-off nature of certain events was due to the fact that they were carried out with funds that were no longer available (e.g. as part of a finalised research project). Regarding the criteria for initiatives to be chosen, designed and distributed throughout the academic year, a general lack of strategy was found. The responses collected are equally imprecise for both the UK and Spain, indicating a dominant opportunistic approach (e.g. economic, due to fund availability; temporary, responding to salient dates such as commemorative days or international years). What the PE units' interviewees did want to make clear is that, above all, it is the researchers' call to get involved or not, and this means that it is often not as strategic as they would like.

Another key issue is the target audiences. Completely different social segments were mentioned in each system. From the PE units, researchers were encouraged not to carry out actions for the general public but to seek specific audiences. These were often the local community and the so-called hard-to-reach groups with limited contact with the university:

Our emphasis and our strategy are for groups that are heard less often: marginalized groups, lower socioeconomic groups, ethnic minorities. We try to encourage projects that link up with those types of groups. (UK3)

In Spain, nine out of the $11 \mathrm{SC}$ units do target their initiatives to the general public, yet they also pay attention to some specific audiences, with special emphasis in children and teenagers, the university community and elderly people. To a lesser extent, other publics such as associations, pre-university teaching staff or people with disabilities were mentioned.

In terms of the formats of activities, initiatives based on the deficit model (one-way) and actions based on dialogue, debate and co-production of knowledge (two-way) were carried out in both systems, although different frequencies were appreciated. PE units put emphasis on two-way activities, while workshops and talks (one-way) were formats par excellence in Spain, where participatory models were less common:

Workshops to explain concepts through practical experiments predominate. These formats are better because they (sic) see the applicability of the concept, participants are immersed in the task and learn in a different way. (E11) ${ }^{7}$

\section{Evaluation}

Evaluation of science communication actions has been found in both systems although with different scenarios. 'Evaluation as an emerging area within PE' - Theme is the theme that summarises the current situation in PE units. There has been a growing interest in measuring medium- and long-term impact of science communication activities in order

\footnotetext{
7 Original quote: 'Predominan talleres de explicación de conceptos mediante experimentos o tareas prácticas. Estos formatos son mejores porque ven (sic) la aplicabilidad del concepto, los participantes se ven inmersos en la tarea y aprenden de otra manera'.
} 
to obtain comparable data over time. Interviewees highlighted the wide range of resources that have been developed and are available for the university community, including courses on how to evaluate, consultancy and support materials, among others. While it cannot be inferred how successful these efforts are, it is clear that evaluation is presented as a key element and that it is rapidly gaining prominence.

So we run courses on monitoring and evaluation. And we talk about different models like the Logic Model for different academics when they are doing engagement to be very clear what the aims, objectives are, etc. and how they would monitor and evaluate that. (UK1)

The Spanish reality, on the other hand, seems to lag behind in this regard. Although all SC units have confirmed doing evaluations for large projects, the responses suggested a very limited concept of evaluation at play. Rather than seeking to measure the social impact of projects, the focus is on metrics on the scope of actions and satisfaction surveys to detect possible improvements. References to deeper evaluations were scarce.

Workshops and festivals, with surveys and participation rates. Audio-visual products, with view count. (E4) ${ }^{8}$

\section{Practical implications of terminology}

We found evidence of practical-level implications of the terminology problem in science communication, which has been extensively addressed in theoretical studies, only in the UK model. On the one hand, interviewees highlighted the difficulty of separating very similar areas and the lack of clarity on where to draw the line to know what was part of their work and what was beyond their role:

Community engagement sits outside what we do but there are elements that overlap with it. (UK2)

On the other hand, it was noted that the academic community has a different view of what PE entails than the practitioners. Interviewees reported that in general, most researchers associate PE exclusively with the deficit model, where interaction with the public is limited to talks or experimental demonstrations.

We are quite conscious of a lot of people thinking public engagement with research equals going to school and doing workshop for kids. (UK2)

However, the professionals who lead the PE units agreed that PE could be defined, in the UK and especially in the university context, as an effort to connect society with current research through participatory formats and with an emphasis on reaching those social sectors that have less interaction with the higher education system.

\section{Future perspectives}

The final question inquired about the long-term perspectives of the units. Although some of the PE units claimed to have strong institutional support, the general feeling was of a

\footnotetext{
${ }^{8}$ Original quote: 'Los talleres y ferias, con encuestas y número de participación. Los productos audiovisuales, por visualizaciones.'.
} 
lack of stability, especially in terms of financial support. Together with the uncertainty of a university system facing potential far-reaching changes, the result is fear around the continuity of the departments ('Lack of stability of the units' - Category). However, five out of the seven UK interviewees did not believe that interest and support for PE would disappear and trusted that in one form or another, it will continue to have a place in UK-based HEIs.

I think the need to show the impact and the value of research is not going to go away in today's society, which means we have to talk about more and show more evidence for that and engaging people in these conversations around that remains quite important.' (UK2)

SC units focussed on the next steps of the way forward, claiming their future actions would be increasing staff numbers, carrying out innovative actions that include changes in formats and public, incorporating citizen science projects and broadening the scope of the initiatives.

\section{Discussion}

The results presented above may indicate that both funders and policies from administrations and other agents influence and shape the development of science communication in the organisational context of HEIs in the UK and Spain. The findings are in line with the results of Schwetje et al. (2020)'s study on German HERIs that found funding bodies to be relevant factors affecting the organisation of HERI communication departments, along with the resources available and the size of the organisation.

The alignment we find between the launch of the units and the main science communication funding calls in both countries suggests that the origin of the institutionalisation of science communication, at a formal level, was not the result of an internal need of the institutions but was driven by external actions at a national level. This is aligned with the FECYT's report (2015) on the Spanish SC unit, which describes the reinforcement of the units as a response to specific actions established by FECYT itself. Likewise, the dissimilar ways in which UK and Spanish science communication units are organised in HEIs seems to be caused by the way in which they are supported by the science communication funding system. The ubiquitous structure observed in the SC units reflects a funding shortage and the FECYT's leadership—so far unquestioned—strengthened through its calls and the establishment of a common framework that has guided the SC's institutionalisation in Spain. On the other hand, the UK knowledge area-based division of tasks and the diversity of jobs are the result of multiple drivers allocating means and resources for PE with certain inconsistency.

These findings contribute to a clearer understanding of how funders and policies directly impact not only on the performance of the units but also on the ways in which institutions are incorporating science communication. Our results also reinforce the statements presented by Koivumäki and Wilkinson (2020), indicating that funding policies that include communication, engagement and impact activities within their remits seem to influence the aims, assumptions and cultures for science communication at both organisational and individual levels.

The HEI's differences in relation to the structure and internal location of the PE/ SC units, as well as the diversity of teams' composition, support the findings of two 
recent studies in HEIs. Firstly, our results are aligned with those of Croucher and Woelert (2021) examining the organisational transformation of HEIs, where the increase in the number and emergence of highly qualified profiles among non-academic staff has been seen to respond to evolving policy and funding settings, as it appears to be the case with PE/SC units. Secondly, our findings reinforce Lepori's work (2021) on the heterogeneity of European HEIs across countries by recognising the diversity of institutions and the influence of their different nature on the configuration of non-academic units or services.

We also find evidence that the inclusion of non-academic impact within the research funding and management scheme acts as a catalyst for a greater integration of PE in HEIs (Owen et al., 2016; Townsley, 2016) and influences its institutional configuration. While the Spanish HE system appears not to be affected by this factor, UK-based HEIs seem to depend to a larger extent on the evaluation of research to be funded. Our data show that the type of the science communication activities carried out in the UK tend to be more collaborative and with bi-directional dialogue. The focus on evaluating science communication activities is also influenced by the need to provide evidence of that impact. Although the real nature of the societal impact of research extends beyond PE, as it seeks to measure how many lives the research itself has affected, researchers believe (wrongly or not) that fostering PE with research amplifies that impact, helping make science communication a popular tool. In fact, this recent interest in science communication as an impact amplifier explains to some extent the specialisation of PE units as 'internal services', putting the emphasis on researchers and their projects. The absence of these factors in the Spanish HE system explains why SC units still work as external services, centralising and controlling the science communication that takes place in the institution with less involvement of research groups. But while research accountability seems to be a driver for PE and PE evaluation at least in the UK, accountability of these units as opposed to the science communication initiatives appears to be an absence in both systems. This corroborates the ideas of Kniola (2013), who suggested that the accountability movement has overlooked other relevant sectors within HEIs such as administrative or non-academic services.

Outreach-understood in this paper as the informal and non-formal activities for children-and its separate execution within UK-based HEIs stands out as one of the elements influencing the UK model. The existing PE-outreach split in the UK gives rise to separate outreach units and leaves room for PE units to focus on other kinds of initiatives. This is not the case in SC units, which usually assume all types of science communication initiatives, including the outreach activities that consume much of their efforts and resources. This limits the Spanish performance.

We identified a predominant deficit style in the Spanish science communication units, with a majority of telling/sharing activities. This analysis is in agreement with the recent Koivumäki and Wilkinson (2020) study in the Finnish context. In contrast, the evolution and specialisation towards the engagement model in the UK HE system is moving the activities away from the deficit style and introducing collaborative formats. This shows a positive difference with respect to the findings by Featherstone et al. (2009) for the PE activities in the academic sector a decade ago. The fact that engagement acquires higher relevance in one HE system than in the other seems to indicate different degrees of maturity regarding the embedding of science communication in HEIs.

In terms of goals, the outreach orientation of Spanish SC units highlights their educational and 'inspiring STEM careers' focus. In contrast, the already mentioned outreach-PE split, together with the emphasis on engaging with the public, reveals the growing attention PE units are giving other aims such as fostering responsible citizenship, encouraging 
critical thinking, increasing public's collaboration in research projects or influencing people's behaviours and attitudes. This is also reflected in the science communication strategies: while in Spanish HEIs there is no strategic thinking on engagement elements, PE acquires a greater weight and is increasingly aligned with the general objectives of the institutions in the UK.

Taken together, our findings present contrasting science communication scenarios at an organisational level that lack homogeneity and have different evolutions and paces. Our results support the statements made by Watermeyer and Lewis (2018) regarding the UK system being constituted by multiple structures and different-sometimes unrelatedactivities, initiatives and programmes and with variations in its level of institutionalisation. Furthermore, our study confirms that these claims apply also to the Spanish HE system. In a similar way, Neresini and Bucchi in 2011 and Entradas et al. in 2020 observed an uneven science communication performance across countries ${ }^{9}$ and research organisations without a true established science communication or engagement culture.

\section{Conclusions}

This empirical, comparative and cross-national study presents an analysis of one of the most recent organisational forms of science communication, namely the specialised units on science communication in the HE context, analysing the UK PE units and the Spanish SC units as a comparative case study. In this article, we characterise the two current management models of science communication in the UK and the Spanish HE systems by the identification of strengths, weaknesses and main drivers. We describe not only what the key influencing factors affecting both models are but how and to what extent they explain the different development and level of embedding of science communication in HEIs.

As for research question one, 'What are the differences and common features among the science communication units of both HE systems from a functional and a structural perspective?', the data show that although there are some exceptions and not all units adhere to a single pattern, there are two general trends, and each trend leads to shared characteristics and key elements that define, on the one hand, the PE management model for the UK HE system and, on the other hand, the SC management model for the Spanish HE system. From a structural perspective, the dissimilar organisation of the science communication units themselves in both HE systems stands out. PE units have a disaggregated configuration, being units split in different hubs, while SC units, on the contrary, have a cohesive configuration, being one central unit within their institutions. While the decentralised model of PE units may need greater efforts for a coherent performance, it is more flexible and addresses more effectively all research areas; the centralised model of SC units offers a more efficient management approach but with an uneven support to different faculties or hubs. From a functional perspective, there are two distinct approaches: on the one hand, 'PE Unit as an Internal Service' - Theme represents PE units as support services for researchers, students and technicians, with the university community itself as the institutional interlocutor with society. On the other hand, 'SC Unit work on behalf of the institution' - Theme describes

\footnotetext{
9 The Entradas et al. study included representation from Brazil, Germany, Italy, Japan, the Netherlands, Portugal, the UK and the USA. Neresini and Bucchi's work had also data from Germany, England and Italy, with minor representation from the Netherlands, Portugal, Spain, Austria, Belgium, Denmark, Finland, France, the Czech Republic, Romania, Sweden and Switzerland.
} 
SC units as representing their HEIs, through their work in centralising, planning and executing most of the initiatives.

Regarding research question two, 'What are the main drivers and key factors influencing science communication organisational forms adopted by HEIs in the Spanish and the UK contexts?', several elements stand out. First, the existing cultures of science communication as well as their historical trajectories influence how Spanish and UK-based HEIs deal with and understand science communication. The dissimilar focus on 'engagement' is one of the main differences between the science communication conceptions of the two systems. The UK paradigm of organisational science communication in HEIs clearly tends to an engagement model, while the Spanish one revolves around the educational side of science communication. This is reflected in the PE-outreach split in the UK that differentiates to some extent the PE units from the SC units. Second, funding bodies and related public policies also set the tone of the institutionalisation process, which therefore has been subjected to the administrations' interests. The specialisation the UK science communication model is undergoing within HEIs is partly due to the inclusion of non-academic impact within the research funding criteria and the corresponding evaluation schemes, while the Spanish model of SC units has been launched and driven by FECYT's initiatives.

These findings help understand better the specific organisational forms of science communication analysed in this paper (PE units and SC units) as well as their evolution, practices and behaviour within the institutions. Overall, our analysis offers an overview of two different science communication management models within the institutional context of HE. Our results show some signs of a 'science communication culture change' embedding in the UK HE system-yet largely dependent on related funding and policies-which indicates a high specialised UK PE model where engagement is progressively gaining ground. Here, PE units have-apparently_a more strategic performance in that sense; however, the units appear to be sometimes lacking a solid anchorage in their organisations, which can prevent them from exploiting all their potential. The Spanish SC model, on the other hand, has made considerable efforts in the last decade; however, the general approach to science communication seems to remain anchored in the deficit model and far from experience a 'culture change' within HEIs. It may be time to ask if, in contrast to the UK situation, the way forward should be a more collaboration-oriented approach among SC units to upgrade to what looks like a better implementation approach for these types of unit.

A complete comparison between both models would require exploring other institutional structures. In UK-based HEIs, PE units live together with several specialised services such as outreach, widening participation and research communication offices. In each Spanish HEI, the central or 'official' SC unit is usually complemented by multiple replicas at the level of faculties, research centres and technology parks or similar. More cross-national studies exploring the different science communication organisational structures and their performances comprising other countries are required in order to achieve a general picture of the cultures of science communication and how they are evolving in institutional settings.

When observing both models, there are clear differences in various aspects, much more than commonalities. These differences arise from the features of scientific culture, the educational system, HE in particular, and the research and development system. This research is focused on reflecting the variety in the management of science communication in the $\mathrm{HE}$, exposing two different models with varying conceptions of the same phenomenon. Here we do not question which of them is better, since this would require an impact evaluation. However, a critical analysis when talking about the units as organisational forms may conclude that, even though there may be ways to improve all units, the PE units' approach 
seems to set the grounds for a more strategic performance in terms of engagement. One reflection that this article may provoke is that science communication must be advanced with a comprehensive approach. Improving the scientific culture level in society requires the coordination of various agents. The challenge for both countries is to clearly identify the role of universities in science communication within the research and development system.

Supplementary Information The online version contains supplementary material available at https://doi. org/10.1007/s10734-021-00801-9.

Acknowledgements The authors acknowledge the collaboration of the science communication professionals who took part in the interviews and would like to thank them for their contributions.

Funding Open Access funding provided thanks to the CRUE-CSIC agreement with Springer Nature. This work was supported by the Universidade da Coruña (UDC) and INDITEX SA under Grant 'INDITEX-UDC 2017 fellowship'.

Availability of data Data is available within the article or its supplementary materials.

\section{Declarations}

Conflict of interest The authors declare no competing interests.

Open Access This article is licensed under a Creative Commons Attribution 4.0 International License, which permits use, sharing, adaptation, distribution and reproduction in any medium or format, as long as you give appropriate credit to the original author(s) and the source, provide a link to the Creative Commons licence, and indicate if changes were made. The images or other third party material in this article are included in the article's Creative Commons licence, unless indicated otherwise in a credit line to the material. If material is not included in the article's Creative Commons licence and your intended use is not permitted by statutory regulation or exceeds the permitted use, you will need to obtain permission directly from the copyright holder. To view a copy of this licence, visit http://creativecommons.org/licenses/by/4.0/.

\section{References}

Beere, A. C., Votruba, J. C., \& Wells, G. W. (2011). Becoming an engaged campus: A practical guide for institutionalizing public engagement. Jossey-Bass. ISBN: 978-0-470-53226-3.

Besley, J. C. (2020). Five thoughts about improving science communication as an organizational activity. Journal of Communication Management, 24(3), 155-161. https://doi.org/10.1108/ JCOM-03-2020-0022

Blanton, J. (2007). Engagement as a brand position in the higher education marketplace. International Journal of Educational Advancement, 7, 143-154.

Bodmer, W. F. (1985). The public understanding of science. Report of a Royal Society ad hoc Group endorsed by the Council of the Royal Society. Royal Society. Retrieved April 9, 2019, from http://royal society.org/uploadedFiles/Royal_Society_Content/policy/publications/1985/10700.pdf

Braun, V., \& Clarke, V. (2006). Using thematic analysis in psychology. Qualitative Research in Psychology, 3(2), 77-101. ISSN:1478-0887.

Chubb, J., \& Watermeyer, R. (2016). Artifice or integrity in the marketization of research impact? Investigating the moral economy of (pathways to) impact statements within research funding proposals in the UK and Australia. Studies in Higher Education, 42(12), 2360-2372.

CICYT (Comisión Interministerial de Ciencia y Tecnología, España.). (2007). Plan Nacional de Investigación Científica, Desarrollo e Innovación Tecnológica 2008-2011.

Croucher, G., \& Woelert, P. (2021). Administrative transformation and managerial growth: A longitudinal analysis of changes in the non-academic workforce at Australian universities. Higher Education. https://doi.org/10.1007/s10734-021-00759-8 
Drori, G. S. (2013). Branding of universities: Trends and strategies. International Higher Education, 71, 3-5.

Duncan, S., \& Manners, P., et al. (2012). Embedding public engagement within higher education: Lessons from the beacons for public engagement in the United Kingdom. In L. McIlrath (Ed.), Higher Education and Civic Engagement (pp. 221-240). Palgrave Macmillan. ISBN 978-1-137-07482-9.

Elken, M., Stensaker, B., \& Dedze, I. (2018). The painters behind the profile: The rise and functioning of communication departments in universities. Higher Education, 76(6), 1109-1122.

Entradas, M., \& Bauer, M. (2017). Mobilisation for public engagement: Benchmarking the practices of research institutes. Public Understanding of Science, 26(7), 771-788. https://doi.org/10.1177/09636 62516633834

Entradas, M., Bauer, M. W., O’Muircheartaigh, C., Marcinkowski, F., Okamura, A., Pellegrini, G., Besley, J., Massarani, L., Russo, P., Dudo, A., Saracino, B., Silva, C., Kano, K., Amorim, L., Bucchi, M., Suerdem, A., Oyama, T., \& Li, Y. (2020). Public communication by research institutes compared across countries and sciences: Building capacity for engagement or competing for visibility? PLoS ONE, 15(7), e0235191. https://doi.org/10.1371/journal.pone.0235191

Featherstone, H., Wilkinson, C., \& Bultitude, K. (2009). Public engagement map: Report to the science for all expert group. Science Communication Unit, University of the West of England.

FECYT (Fundación Española para la Ciencia y la Tecnología). (2012). Libro blanco de las unidades de cultura científica y de innovación UCC $+i$. Retrieved December 17, 2017, from https:/www.fecyt.es/ es/node/2159/pdf-viewer

FECYT. (2015). UCC $+i$ : origen y evolución (2007-2014). Retrieved December 21, 2017, from https:// www.fecyt.es/es/node/3271/pdf-viewer

Fereday, J., \& Muir-Cochrane, E. (2006). Demonstrating rigor using thematic analysis: A hybrid approach of inductive and deductive coding and theme development. International Journal of Qualitative Methods, 5(1), 80-92.

Ferrando González, L., \& Tigeras Sánchez, P. (2015). Cultura científica, cultura democrática. Quaderns de la Fundació Dr. Antoni Esteve. El científico ante los medios de comunicación. Retos y Herramientas Para Una Cooperación Fructífera, 28, 85-95.

Fitzgerald, H. E., Bruns, K., Sonka, S. T., Furco, A., \& Swanson, L. (2012). The centrality of engagement in higher education. Journal of Higher Education Outreach and Engagement, 16(3), 7-27. ISSN 1534-6104.

Furco, A. (2010). The engaged campus: Toward a comprehensive approach to public engagement. British Journal of Educational Studies, 58(4), 375-390. https://doi.org/10.1080/00071005.2010.527656

House of Lords. (2000). Science and society: Third report of session 1999-2000, House of Lords Select Committee on Science and Technology. HL38. Retrieved April 11, 2019. http://pubs1.tso.parliament. uk/pa/ld199900/ldselect/ldsctech/38/3801.htm

Hughes, A., \& Kitson, M. (2012). Pathways to impact and the strategic role of universities: New evidence on the breadth and depth of university knowledge exchange in the UK and the factors constraining its development. Cambridge Journal of Economics, 36, 723-750. https://doi.org/10.1093/cje/bes017

Javadi, M., \& Zarea, K. (2016). Understanding thematic analysis and its pitfall. Journal of Client Care, 1(1), 34-40. https://doi.org/10.15412/J.JCC.02010107

Kniola, D. J. (2013). Accountability through assessment of administrative organizations in higher education. European Journal of Higher Education, 3(1), 89-101. https://doi.org/10.1080/21568235.2013.778044

Koivumäki, K., \& Wilkinson, C. (2020). Exploring the intersections: Researchers and communication professionals' perspectives on the organizational role of science communication. Journal of Communication Management, 24(3), 207-226.

Lepori, B. (2021). The heterogeneity of European Higher Education Institutions: A configurational approach. Studies in Higher Education. https://doi.org/10.1080/03075079.2021.1968368

Lo Presti, L., \& Marino, V. (2019). Is online public engagement a new challenge in the university communication plan? A managerial perspective. Studies in Higher Education, 45(7), 1380-1397. https://doi.org/ 10.1080/03075079.2019.1619680

Molas-Gallart, J., Salter, A., Patel, P., Scott, A., \& Duran, X. (2002). Measuring third stream activities. Final report to the Russell Group of University. SPRU-Science and Technology Policy Research, University of Sussex.

Neresini, F., \& Bucchi, M. (2011). Which indicators for the new public engagement activities? An exploratory study of European research institutions. Public Understanding of Science, 20(1), 64-79. https:// doi.org/10.1177/0963662510388363

Ojeda-Romano, G., \& Fernández-Marcial, V., et al. (2018). Universidades públicas y divulgación científica: análisis de las Unidades de Cultura Científica e Innovación. In A. Cuevas Badallo (Ed.), Cultura 
científica y cultura tecnológica: Actas del IV Congreso de Filosofía de la Ciencia y la Tecnología (pp. 203-208). Ediciones Universidad de Salamanca. ISBN: 978-84-9012-911-1.

Owen, D., Featherstone, H., \& Leslie, K. (2016). The state of play: Public engagement with research in UK universities. Research Councils UK and Wellcome Trust.

Parejo Cuéllar, M., Martín Pena, D., \& Vivas Moreno, A. (2017). La divulgación científica: Estructuras y prácticas en las universidades. Editorial Gedisa S.A. eISBN: 978-84-9784-314-0

Pinheiro, R., Langa, P. V., \& Pausits, A. (2015). The institutionalization of universities' third mission: Introduction to the special issue. European Journal of Higher Education, 5(3), 227-232. https://doi.org/10. $1080 / 21568235.2015 .1044551$

Ravn, T. Mejlgaard, N. \& Rask, M. (2014). Inventory of PE mechanisms and initiatives D.1.1. (PE2020) Public Engagement Innovations for Horizon 2020. Retrieved April 3, 2019, from http://pe2020.eu/

Reed, M. S., Duncan, S., Manners, P., Pound, D., Armitage, L., Frewer, L., Thorley, C., \& Frost, B. (2018). A common standard for the evaluation of public engagement with research. Research for All, 2(1), 143-162. https://doi.org/10.18546/RFA.02.1.13

Roca Marín, D. (2017). Divulgación Científica en la Universidad desde su Contextualización Histórica: Estudio de Caso y Propuesta de un Modelo de Divulgación para la Universidad de Murcia. Universidad de Murcia.

Rodder, S. (2020). Organisation matters: Towards an organisational sociology of science communication. Journal of Communication Management, 24(3), 169-188. https://doi.org/10.1108/ JCOM-06-2019-0093

Rowe, G., \& Frewer, L. J. (2005). A typology of public engagement mechanisms. Science, Technology, and Human Values, 30(2), 251-290. https://doi.org/10.1177/0162243904271724

Royal Society. (2006). Survey of factors affecting science communication by scientists and engineers. Final report. London.

Schäfer, M. S., \& Fähnrich, B. (2020). Communicating science in organizational contexts: Toward an "organizational turn" in science communication research. Journal of Communication Management, 24(3), 137-154. https://doi.org/10.1108/JCOM-04-2020-0034

Schwetje, T., Hauser, C., Böschen, S., \& Leßmöllmann, A. (2020). Communicating science in higher education and research institutions: An organization communication perspective on science communication. Journal of Communication Management, 24(3), 189-205. https://doi.org/10.1108/ JCOM-06-2019-0094

Townsley, R. (2016). Interim review of the public engagement with research catalysts programme 2012 to 2015. Research Councils UK. Retrieved March 14, 2018, from www.ukri.org/files/legacy/skills/ rcukpercatalystsprogrammeinterimsummary-pdf/

Trench, B. (2017). Universities, science communication and professionalism. Journal of Science Communication, 16(05), C02.

Vaismoradi, M., \& Snelgrove, S. (2019). Theme in qualitative content analysis and thematic analysis. $F Q S, 20(3), 23$.

Vargiu, A. (2014). Indicators for the evaluation of public engagement of higher education institutions. Journal of the Knowledge Economy, 5, 562-584. https://doi.org/10.1007/s13132-014-0194-7

Watermeyer, R. (2012). From engagement to impact? Articulating the public value of academic research. Tertiary Education and Management, 18(2), 115-130. https://doi.org/10.1080/13583883.2011. 641578

Watermeyer, R. (2014). Issues in the articulation of 'impact': The responses of UK academics to 'impact' as a new measure of research assessment. Studies in Higher Education, 39(2), 359-377. https://doi.org/10.1080/03075079.2012.709490

Watermeyer, R. (2015). Lost in the 'third space': The impact of public engagement in higher education on academic identity, research practice and career progression. European Journal of Higher Education, 5(3), 331-347. https://doi.org/10.1080/21568235.2015.1044546

Watermeyer, R. (2016). Public intellectuals vs. new public management: The defeat of public engagement in higher education. Studies in Higher Education, 41(12), 2271-2285. https://doi.org/10. 1080/03075079.2015.1034261

Watermeyer, R., \& Hedgecoe, A. (2016). Selling 'impact': Peer reviewer projections of what is needed and what counts in REF impact case studies. A retrospective analysis. Journal of Education Policy, 31(5), 651-665. https://doi.org/10.1080/02680939.2016.1170885

Watermeyer, R., \& Lewis, J. (2018). Institutionalizing public engagement through research in UK universities: Perceptions, predictions and paradoxes concerning the state of the art. Studies in Higher Education, 43(9), 1612-1624. https://doi.org/10.1080/03075079.2016.1272566 
Watermeyer, R., \& Tomlinson, R. (2021). Competitive accountability and the dispossession of academic identity: Haunted by an impact phantom. Educational Philosophy and Theory. https://doi.org/10. 1080/00131857.2021.1880388

Webster, T., Dyball, M. \& King, S. (2010). Independent Review of Beacons for Public Engagement Evaluation Findings. Final Report for RCUK, HEFCE and the Wellcome Trust. People Science and Policy. Retrieved January 7, 2018, from https://www.ukri.org/files/legacy/scisoc/beaconsevaluati onreviewfinalreport-pdf/

Weingart, P., \& Joubert, M. (2019). The conflation of motives of science communication - causes, consequences, remedies. Journal of Science Communication, 18(03), Y01. https://doi.org/10.22323/2. 18030401

Wilkinson, C. (2017). Evidencing impact: A case study of UK academic perspectives on evidencing research impact. Studies in Higher Education, 44(1), 1-14.

Publisher's note Springer Nature remains neutral with regard to jurisdictional claims in published maps and institutional affiliations. 